\title{
HELLP SYNDROME - A diagnostic dilemma
}

\author{
S Yeasmin ${ }^{1}$, R Nazneen ${ }^{2}$, S Akhter ${ }^{3}$, N Jahan ${ }^{4}$
}

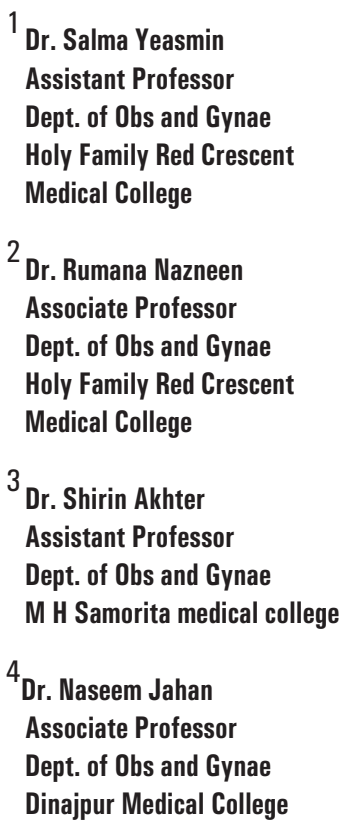

Correspondence

Dr. Salma Yeasmin Assistant Professor Dept. of Obs and Gynae Holy Family Red Crescent Medical College \& Hospital E-mail : drsalma85@gmail.com

\section{Introduction}

HELLP Syndrome is a life threatening obstetrical condition usually a variant or complication of pre-eclampsia. It is characterized by hepatic endothelial disruption followed by platelet activation, aggregation and consumption, ultimately resulting in ischemia and hepato cellular death.

HELLP syndrome usually begins during third trimester. Rare cases have been reported as early as 21 weeks or early post partum period $^{1,2,3}$. HELLP Syndrome and pre-eclampsia both occur in latter stage of pregnancy or sometimes after childbirth.

The acronym of HELLP was coined by Weinstein in 1982 to describe this syndrome. HELLP is an abbreviation of the three (3) main features:

$\mathrm{H}$ - Haemolysis

El- Elevated Liver Enzyme

LP- Low Platelet Count. ${ }^{4}$

HELLP syndrome was identified as a distinct clinical entity (as opposed to severe preeclampsia) by Dr. Louis Weinstein in $1982 .{ }^{5}$

In a 2005 article, Weinstein wrote that the unexplained postpartum death of a woman who had haemolysis, abnormal liver function, thrombocytopenia, and hypoglycemia motivated him to review the medical literature and to compile information on similar woman. ${ }^{6}$

\section{Epidemiology}

Its incidence is reported as $0.5-0.9 \%$ of all pregnancies, and $10-20 \%$ of women with severe preeclampsia. ${ }^{1} \mathrm{HELLP}$ develops in approximately 0.1 to 0.8 percent of pregnancies overall and in 10 to 20 percent of women with severe preeclampsia/eclampsia. ${ }^{7}$ HELLP usually occurs in Caucasian women over the age of $25 .{ }^{8}$

HELLP Syndrome occurs in $0.2 \%$ to $0.6 \%$ of all pregnancies. This syndrome may be the first warning of preeclampsia which may be confused with Hepatitis or thrombotic thromcytopenic purpura. Maternal Mortality is estimated to be high as $2 \%-24 \%$. Perinatal Mortality is also high ranging from $9 \%-65 \% .^{9}$

\section{Risk Factors}

There is no single cause for this condition. Instead, the medical community widely recognizes various risk factors that may increase the chances of developing HELLP syndrome.

Preeclampsia is the greatest risk factor. This condition is marked by high blood pressure, and it occurs during the last trimester of pregnancy. However, not all pregnant women with preeclampsia will necessarily develop HELLP syndrome.

Other risk factors include: Age of 25, Caucasian, multi para, obesity, poor diet, lack of exercise, diabetes. ${ }^{10}$

\section{Pathophysiology}

The exact pathological mechanism is unknown, but general activation of the coagulation cascade is considered the main underlying problem. Fibrin forms cross linked networks in the small blood vessels. This leads to a micro angiopathic hemolytic anemia: the mesh causes destruction of red blood cells as if they were being forced through a strainer. Additionally, platelets are consumed. As the liver appears to be the main site of this process, downstream liver cells suffer ischemia, leading to periportal necrosis. Other organs can be similarly affected. HELLP syndrome leads to a variant form of disseminated intravascular coagulation (DIC), leading to paradoxical bleeding, which can make emergency surgery a challenge. ${ }^{11}$

The Elevated Liver Enzyme levels in the syndrome are thought to be secondary to obstruction of hepatic blood flow by fibrin 
deposits in the sinusoids. This obstruction leads to periportal necrosis and, in severe cases, intrahepatic hemorrhage, subcapsular hematoma formation or eventual rupture of Glisson's capsule.

Spontaneous rupture of a Subcapsular liver haematoma in pregnancy is a rare, but life threatening complication. Rupture most often occurs in the right liver lobe. ${ }^{9}$

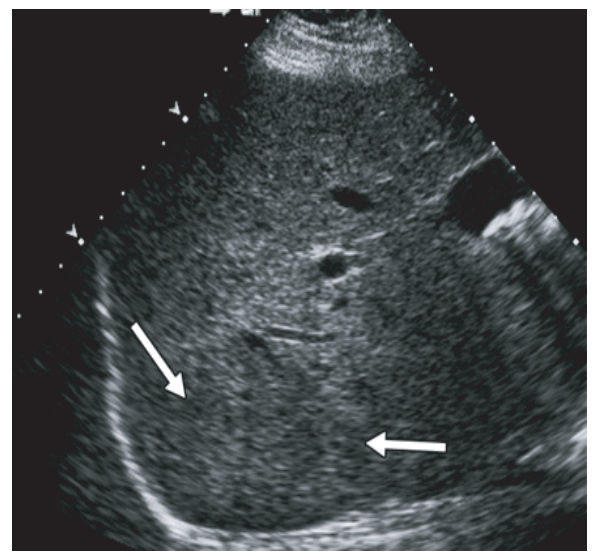

\section{Clinical features}

Feeling generally unwell or fatigued $80 \%-90 \%$, abdominal pain especially upper right side/below ribs, nausea, vomiting 30\%$90 \%$, headache $33-61 \%$, may also have swelling in the hands or face, weight gain, blurring vision/ visual disturbance $17 \%$, heart burn or indigestion, shoulder tip pain, pain when breathing deeply. In rare cases nose bleeds or other bleeding and seizures.

On physical examination - Right upper quadrant tenderness present in $90 \%$, edema is not a useful marker, increase blood pressure $(82-88 \%)$ and proteinuria found in $(86-100 \%)^{12}$

\section{Classification}

\section{TENNESSEE classification}

Based on laboratory criteria $\bullet$ Platelet count $<100,000 / \mu \mathrm{L}$, $\bullet$ AST $70 \mathrm{IU} / \mathrm{L} \& \bullet \mathrm{LDH} 600 \mathrm{IU} / \mathrm{L}$. Hemolysis on peripheral smear.

Partial HELLP includes presence of any 2 of the 3 criteria - can be managed by conservative treatment.

Full HELLP includes all of the 3 criteria $^{13}, 14$ - high risk group for complications like DIC and should be considered delivery within 48 hours.

\section{MISSISSIPI classification (2006)}

\section{CLASS I -}

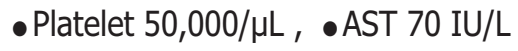

- LDH $600 \mathrm{IU} / \mathrm{L}$, Hemolysis on smear - are at higher risk for maternal morbidity and mortality.

\section{CLASS II-}

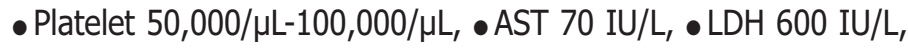
Hemolysis on smear.

\section{CLASS III-}

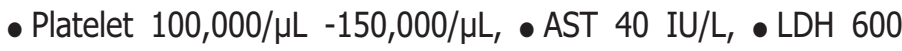
$\mathrm{IU} / \mathrm{L}$, Hemolysis on smear.

CLASS II \& III are considered as clinical significant transitional stage.

Haemolysis - Peripheral smear shows Spherocyte, Schistocyte, Triangular cell, Barr cell.

Liver function test- Total billirubin->1.2mg\%, LDH->600 IU/Litre. Level of AST or ALT->150 IU/L associated with increased maternal morbidity or mortality.

\section{Low platelet count}

Platelet count $<150000 / \mathrm{cu} \mathrm{mm}$, Leukocytosis. Coagulation Factors- If DIC is not present - PT, APTT, S. Fibrinogen will be normal. If fibrinogen is $<300 \mathrm{mg} / \mathrm{dl}$ along with other laboratory abnormality DIC is suspected. Positive D-dimer test is more sensitive indicator of subclinical coagulopathy. S Uric AcidIncreased.

Hypoglycemia-Persistent, Profound hypoglycemia inspite of repeated glucose transfusion is peculiar to $H$. Syndrome Proteinuria ${ }^{12}$.

\section{Differential Diagnosis}

Disease related to pregnancy- Acute fatty liver of pregnancy, Gestational thromocytopaenia, Benign thromocytopaenia of pregnancy, Acute Exacerbation of SLE. Haemolytic uraemic syndrome

Infection and inflammatory diseases not related to pregnancyViral Hepatitis. Cholecystisis, Upper UTI, Gastric Ulcer, Acute Pancreatitis.

\section{Maternal Complications-}

- Acute Renal Failure,

- DIC,

- Severe Ascites,

- Cerebral Oedema,

- Pulmonary Oedema,

- Abruptio Placenta,

- Eclampsia,

- Sub capsular liver haematoma,

- Liver Rupture,

- Hepatic Infarction,

- Retinal Detachment,

- Cerebral Haemorrhage,

- Maternal Death. 


\section{Fetal/Neonatal Complication-}

- Pre-term delivery,

- IUGR,

- Neonatal Thrombocytopenia,

- RDS,

- Perinatal Death. ${ }^{13}$

HELLP Syndrome can be managed by Corticosteroid, Magnesium Sulfate, Hypotensive Drug, Blood Product and delivery.

\section{Eligibility to Conservative Management includes}

- Controlled Hypertension at less than 160/110 mm hg.

- Oliguria responds to fluid management .

- Class II -III (platelet count) >50000

\section{Corticosteroids}

Corticosteroid therapy should be instituted in patients with HELLP syndrome who have a platelet count of less than 100,000 per $\mathrm{mm}^{3}$ and should be continued until liver function abnormalities are resolving and the platelet count is greater than 100,000 per mm. ${ }^{3,15}$

The antenatal administration of dexamethasone (Decadron) in a high dosage of $10 \mathrm{mg}$ intravenously every 12 hours has been shown to markedly improve the laboratory abnormalities associated with HELLP syndrome. ${ }^{14}$

Steroids given antenatally do not prevent the typical worsening of laboratory abnormalities after delivery. However, laboratory abnormalities resolve more quickly in patients who continue to receive steroids postpartum. ${ }^{16}$

Intravenously administered dexamethasone appears to be more effective than intramuscularly adminstered betamethasone for the antepartum treatment of mothers with HELLP syndrome. ${ }^{17}$

\section{Proposed mechanism of action of steroids}

Diminish oedema, inhibit endothelial activation and reduce endothelial dysfunction. Prevents thrombotic microangiopathic anaemia. Inhibits cytokine production. Induce anti-inflammatory effects in the HELLP syndrome. In addition to accelerate foetal lung maturity, antenatal steroid has been used to reduce the risk of IVH and NEC in selected cases of the HELLP syndrome.

Dosing Schedule For most of patient with HELLP syndrome-

$10 \mathrm{mg}$ IV dexamethasone every $12 \mathrm{hrs}$ until delivery \& then

$10 \mathrm{mg}$ IV dexamethasone every 12 hrs for additional 3 doses post partum.
For selected high risk cases with profound thrombocytopenia with CNS dysfunction.

20mg IV dexamethasone every 6hrs up to 4 doses

\section{Magnesium Sulphate}

Patients with HELLP syndrome should be treated prophylactically with magnesium sulphate to prevent seizures.

Antihypertensive therapy should be initiated if blood pressure is consistently greater than $160 / 110 \mathrm{~mm} \mathrm{Hg}$ despite the use of magnesium sulfate. The goal is to maintain diastolic blood pressure between 90 and $100 \mathrm{~mm} \mathrm{Hg}$.

The most commonly used antihypertensive agent has been: Hydralazine, Labetolol, Nifedipine

\section{Blood Products}

Between $38-93 \%$ of patients with HELLP syndrome receive some form of blood product. Patients with a platelet count greater than 40,000 per $\mathrm{mm}^{3}$ are unlikely to bleed. Patients who undergo cesarean section should be transfused if their platelet count is less than 50,000 per $\mathrm{mm}^{3}$

Prophylactic transfusion of platelets at delivery does not reduce the incidence of postpartum hemorrhage or hasten normalization of the platelet count. Patients with DIC should be given fresh frozen plasma and packed red blood cells.

\section{Management of post-partum HELLP syndrome}

In most women with a HELLP syndrome, the maternal Platelet counts continue to decrease immediately post-partum with an increasing trend on the third day.

About $30 \%$ of the HELLP syndromes develop after birth.

The time of onset ranged from few hours to 7 days; the majority within the first 48 hours after delivery.

In post-partum HELLP syndrome, risk of renal failure and pulmonary oedema is significantly increased.

Since early post-partum administration of high-dose corticosteroids might accelerate recovery, its routine administration is highly advocated (10 mg of dexamethasone every 12 hours) Women with a HELLP syndrome who demonstrate progressive elevation of bilirubin or creatinine for more than 72 hours after delivery may benefit from plasma exchange with fresh frozen plasma. In the case of continuing haemolysis, persistent thrombocytopenia and hypoproteinaemia, post-partum erythrocyte and thrombocyte substitution, as well as albumin supplementation are standard treatment regimens. 


\section{Risk of Recurrence and Preconception Counselling}

Sibai has shown that oral contraceptives are safe in women with a prior HELLP syndrome. ${ }^{7}$ Women with a history of the HELLP syndrome carry an increased risk of at least 20\% (range $5-52 \%$ ) that some form of gestational hypertension will recur in a subsequent gestation.

If someone wants contraception, Oral Contraceptive Pill is safe with history of HELLP syndrome.

Women with a history of HELLP syndrome at or before 28 weeks' gestation during the index pregnancy are at increased risk for several obstetric complications (preterm birth, pregnancy-induced hypertension and increased neonatal mortality) in a subsequent pregnancy. ${ }^{13}$

\section{Conclusion}

HELLP Syndrome and its management still poses a problem in modern obstetrics as exact etiology of this disease is unknown. Initially symptoms are more like flu so we obstetricians must be very alert if any pregnant women visit at her $2^{\text {nd }}$ or $3^{\text {rd }}$ trimester with flu like syndrome. Those patients should be evaluated by two simple tests CBC and Liver Enzyme. This is the only way for early diagnosis and for starting early management and thereby we can decrease the fatality of the disease.

\section{References}

1. Rahman TM, Wendon J. Severe hepatic dysfunction in pregnancy. Q J Med. 2002;95:343:[Medline

2. Lichtman, M, Kipps T, Seligsohn U, Kaushansky K, Prchal J. Hemolytic Anemia resulting from physical Injury to Red Cells. In: Williams Hematology, Eighth Edition. 8. McGraw-Hill Companies; 2010:Chapter 50

3. Weinstein L. Syndrome of hemolysis, elevated liver enzymes, and low platelet count: A severe consequence of hypertension in pregnancy. Am J Obstet Gynecol. 1982;142:159. [Medline].

4. Haram K, Svendsen E, Abildgaard U (Feb 2009). "The HELLP syndrome: clinical issues and management. A review". BMC Pregnancy Childbirth 9: 8. doi:10.1186/1471-2393-9-8. PMC 2654858. PMID 19245695

5. Weinstein $L$ (1982). "Syndrome of hemolysis, elevated liver enzymes, and low platelet count: a severe consequence of hypertension in pregnancy". Am J Obstet Gynecol 142 (2): 159-67. PMID 7055180

6. Weinstein L (Sep 2005). "It has been a great ride: the history of HELLP syndrome". Am J Obstet Gynecol 193 (3 Pt 1): 860-3. doi:10.1016/ j.ajog.2005.06.058. PMID 16150288

7. Sibai B M. HELLP syndrome. Up to date .Wolters Kluwer Health. Aug 2014.

8. Padden MO (Sep 1999). "HELLP syndrome: recognition and perinatal management". Am Fam Physician 60 (3): 829-36, 839. PMID 10498110

9. Journal of Liver Disease in Pregnancy-(NIH) N.America 1996.

10. HELLP syndrome. (2009, March). American Pregnancy Association. Retrieved July 12, 2012, from http://www.americanpregnancy.org/pregnancy complications/hellpsyndrome.html.

11. Http://www.adhb.govt.nz/newborn/Guidelines/Maternal/MaternalHELLPAndAFLP.htm
12. Dr. Baha M. Sibai . HELLP Syndrome - Diagnosis and Management. womenshealthsection.com/visited on 9.12 .14

13. Sibai BM (Feb 1990). "The HELLP syndrome (hemolysis, elevated liver enzymes, and low platelets)". Am J Obstet Gynecol 162 (2): 311-6. doi:10.1016/0002-9378(90)90376-i. PMID 2309811

14. Audibert F, Friedman SA, Frangieh AY, Sibai BM (Aug 1996). "Clinical utility of strict diagnostic criteria for the HELLP (hemolysis, elevated liver enzymes, and low platelets) syndrome". Am J Obstet Gynecol 175 (2): 460-4. doi:10.1016/s0002-9378(96)70162-x

15. Magann EF, Perry KG Jr, Meydrech EF, Harris RL, Chauhan SP, Martin JN Jr. Am J Obstet Gynecol 1994;171:1154-8

16. Magann EF, Bass D, Chauhan SP, Sullivan DL, Martin RW, Martin JN Jr. Am J Obstet Gynecol 1994;171:1148- 53.

17. (Am J Obstet Gynecol 2001;184:1332-9.). 